\title{
Rawls' Idea of Public Reason and Democratic Legitimacy
}

Fabienne Peter ${ }^{1}$, Department of Philosophy, University of Warwick

Paper published in Journal of International Political Theory 3 (1), 2007, pp. 129-143; special issue on Kantian Aspects of Practical Normativity

\section{Introduction}

Rawls' idea of public reason has attracted a host of criticisms. Some have objected to this idea that it is overly narrow and excludes contributions to the process of public deliberation which should not be excluded. Others have taken issue with the idea of public reason as freestanding - as making no reference to comprehensive (moral, religious, etc.) doctrines. Still others have argued that Rawls' idea of public reason is incomplete - that there are issues to be settled in political discussion which public reason cannot settle. Defenders of Rawls have attempted to respond to these objections and to argue that his idea of public reason can fulfill the tasks Rawls attributes to it.

In my view, these debates tend to fail to get to the core of the problem because they fail to address the relationship between Rawls' idea of public reason and his conception of democratic legitimacy. Rawls' own comments on this relationship are not always clear and he also seems to have changed his view on this issue over time. This has exacerbated confusion about his idea of public reason.

\footnotetext{
${ }^{1}$ I am most grateful to Sorin Baiasu for his helpful comments. I have also benefitted very much from discussions with the other participants of the Manchester workshop and with Matthew Clayton and Susan Hurley. Finally, I would like to thank an anonymous referee for detailed suggestions.
} 
In this paper, I want to focus on the relationship between Rawls' idea of public reason and democratic legitimacy. I shall limit myself to the dominant paradigm in democratic theory today - deliberative democracy. In Rawls' account, as Samuel Freeman (2000: 379) puts it, "deliberative democracy is a moral requirement of political legitimacy". And public reason is an essential element in Rawls' account of deliberative democracy. ${ }^{2}$ It thus has an important role to play in his conception of democratic legitimacy. My aim in this paper is to provide an indirect defense of Rawls' idea of public reason - one that focuses on his conception of democratic legitimacy and the role of public reason within that.

In a first step, I shall identify two categories of conceptions of democratic legitimacy. What distinguishes them is how they characterize the relation between legitimacy and political justification. According to conceptions of a first category, I call it Pure Proceduralism, a democratic decision is legitimate, whatever its content, if it is the result of an appropriately constrained decision-making process. The conditions that constrain the process need to be justified on the basis of reasons acceptable to all. According to conceptions of a second category, I call it Rational Proceduralism, justification must extend to the content of the decisions themselves. Rawls' conception of legitimacy demands public reason: "our exercise of political power is proper and hence justifiable only when it is exercised in accordance with a constitution the essentials of which all citizens may reasonable expected to endorse in the light of principles and ideals

\footnotetext{
2 “ $[\mathrm{t}]$ here are three essential elements of deliberative democracy. One is an idea of public reason.... A second is a framework of constitutional democratic institutions that specifies the setting for deliberative legislative bodies. The third is the knowledge and desire on the part of the citizens generally to follow public reason..." (Rawls 1999: 580).
} 
acceptable to them as reasonable and rational. This is the liberal principle of legitimacy" (Rawls 1993: 217). ${ }^{3}$

But what role does his idea of public reason play in the conception of democratic legitimacy? Is it meant to justify the constraints the democratic decision-process has to satisfy or to democratic decisions themselves? In a second step, of the paper, I shall distinguish between two ways of interpreting Rawls' idea of public reason, and argue that they correspond to the two interpretations of the requirements of democratic legitimacy.

Since Rawls makes it clear that public reason applies to the justification of constitutional essentials and matters of basic justice (Rawls 1999: 575), the question has to be answered as to how the political justification of constitutional essentials and matters of basic justice relates to the legitimacy of specific policy proposals and new laws as they are made in the course of the democratic process. On one interpretation, call this the substantive interpretation of Rawls' idea of public reason, the political justification of constitutional essentials and matters of basic justice has to extend to the substantive justification of democratic decisions. In this view, the legitimacy of a particular decision will depend on its conformity with the content of public reason. This is consistent with Rational Proceduralism. Rawls can sometimes be read to endorse this interpretation. I shall argue that this is not the interpretation we should favor and indeed the one which explains the many objections that have been leveled against Rawls' idea of public reason.

An alternative interpretation of the Rawlsian project restricts public reason to the justification of the constraints that frame the decision-making process in a

\footnotetext{
${ }^{3}$ Elsewhere he writes: "A liberal conception of political legitimacy aims for a public basis of justification and appeals to free public reason" (Rawls 2001: 186).
} 
deliberative democracy. In this view, call it the procedural interpretation of Rawls' idea of public reason, democratic decisions are legitimate if they are the outcome of an appropriately constrained deliberative process. Public reason is invoked when it comes to the political justification of the principles that should govern the process of democratic decision-making, but not - at least not directly - in relation to the content of public deliberation. Many passages in Rawls' writings suggest this procedural interpretation - i.e. an interpretation of public reason that is consistent with Pure Proceduralism. By interpreting Rawls' idea of public reason in this way, I shall defend it against his critics.

\section{Democratic Legitimacy}

An exchange of reasons for and against specific proposals is the raison d'etre of deliberative democracy and distinguishes it from the rival conception of aggregative democracy. This is recognized by all writers on the subject. Joshua Cohen (1989: 22), for example, influentially characterized the dependence of deliberative democracy on an exchange of reason in the following way.

"Deliberation is reasoned in that the parties to it are required to state their reasons for advancing proposals, supporting or criticizing them. They give reasons with the expectation that those reasons (and not, for example, power) will settle the fate of their proposal."

This exchange of reasons somehow relates to the legitimacy of democratic decision. The question is how. In a society characterized by pluralism, how exactly to conceive of the relation between the exchange of reason in the democratic process and legitimacy is not an easy task. It is affected by what Rawls calls "the problem of political legitimacy" (Rawls 2001: 40). According to Rawls, in democratic societies, political power "is regarded as the power of free and equal citizens" (Rawls 2001: 
40). This is a first fact of liberal societies. A second fact is that of reasonable pluralism. Together, they give rise to the following problem. If legitimacy demands that political power is exercised by free and equal citizens and if these citizens hold a plurality of conceptions of the good, "in the light of what reasons and values ... can citizens legitimately exercise ... coercive power over one another" (Rawls 2001: 41)? Before I discuss Rawls' own solution to this problem, let me first say a little bit more on legitimacy.

In the aftermath of the publication of A Theory of Justice, Anglo-American political philosophy has been focusing on the concept of justice. This seems to be changing. The concept of legitimacy is attracting increasing attention in recent political theory and political philosophy. I take legitimacy to be the normative core of the idea of democracy. It specifies how democratic decisions should be made, just like justice specifies how goods should be distributed. In this normative interpretation, a conception of democratic legitimacy identifies the conditions that have to be satisfied in democratic-decision making. The normative interpretation of democratic legitimacy differs from a Weberian descriptive interpretation. In the descriptive sense, legitimacy prevails as long as people support - or at least do not challenge democratic institutions and decisions. In the normative interpretation, legitimacy prevails as long as people have reasons to support or not to challenge them.

In contemporary political philosophy, interest in the concept of legitimacy was revived with the emergence of the paradigm of deliberative democracy. ${ }^{4}$ As the literature on deliberative democracy and on democratic legitimacy increases rapidly, there is also an increasing diversity of conceptions of democracy and of interpretations of the requirements of political legitimacy. I have argued elsewhere

\footnotetext{
${ }^{4}$ Early contributions include Manin (1987), Cohen (1989).
} 
that the multitude of conceptions of legitimacy can be divided into two broad categories depending on how much normative weight they place on procedures relative to substantive considerations about the quality of the outcomes of these processes. $^{5}$

Conceptions of democratic legitimacy of a first category treat a decision as legitimate if it has been reached in a fair deliberative process and if all members of the democratic collective have reasons to endorse it, or, weaker, if at least no one can reject it with good reasons (Cohen 1989). Such conceptions of legitimacy thus combine two sets of conditions: conditions that apply to the process of decisionmaking and conditions that apply to its outcome. The first set of conditions are primarily conditions of "political fairness" or "political equality" (Beitz 1989). They demand that democratic decisions be the result of an equal consideration of individual interests. The second set of conditions refers to the substantive justifiability of the outcomes of the democratic process. Because the substantive justification of collective decisions is seen as essential to democratic legitimacy, political legitimacy is not only "backwards looking" - towards the conditions under which a decision was reached - but also includes considerations of the rational quality of the outcomes chosen. I call conceptions of this category Rational Proceduralist conceptions of legitimacy.

A famous example of Rational Proceduralism is the interpretation of deliberative democracy propagated by Juergen Habermas $(1990,1996)$. In his version, public deliberation, if properly conducted, leads to rationally justified policy decisions. Drawing from discourse ethics, the conditions Habermas suggests we impose on the deliberative process reflect the demands of intersubjective rational

\footnotetext{
${ }^{5}$ See Peter (2007). The following passages draw on that article.
} 
justification. Rational justification in discourse ethics focuses on what "all can will in agreement to be a universal [moral] norm" (Habermas 1990: 67). Applied to democracy this view makes deliberation constitutive of rational justification and, conversely, regards rational justification as essential to deliberative democracy and as the distinctive feature that set it apart from alternative conceptions of state and society. ${ }^{6}$

In Habermas' version of Rational Proceduralism, considerations of political fairness and of rational justification intertwine and jointly determine democratic legitimacy: „Deliberative politics acquires its legitimating force from the discursive structure of an opinion- and will-formation that can fulfil its socially integrative function only because citizens expect its results to have a reasonable quality" (Habermas 1996: 304).

Philip Pettit defends a different version of Rational Proceduralism. His work with Christian List draws attention to obstacles to the rationalizing potential of deliberative democracy, even under ideal circumstances. Pettit and List argue that occurrences of the so-called discursive dilemma may undermine the rationality of the outcome of public deliberations. ${ }^{7}$ This problem arises when the evaluation of alternative outcomes is logically connected to a set of independent premises - for example when the decision to build a new communal centre depends on the perceived need for this in the community and an evaluation of the appropriateness of the site.

\footnotetext{
${ }^{6}$ According to Habermas (1996: 296), "practical reason ... resides in ... in the rules of discourse and forms of argumentation that borrow their normative content from the validity basis of action oriented to reaching understanding.” And he adds (1996: 300) that „the procedures and communicative presuppositions of democratic opinion- and will-formation function as the most important sluices for the discursive rationalization of the decisions of an administration bound by law and statute“.

${ }^{7}$ See Pettit (2001a, b); List and Pettit $(2002,2004)$.
} 
The dilemma turns on the possibility that a collective decision may clash with the separate evaluation of the individual premises - i.e. on the possibility that there is both a majority who agrees that there is such a need and a majority who agrees that the site is appropriate, but, if asked directly, the majority decides that the centre should not be built. The problem is best represented for the simple case of three individuals $\mathrm{A}, \mathrm{B}$, and $\mathrm{C}$ :

\begin{tabular}{|l|l|l|l|}
\hline & Need? & Site ok? & Build? \\
\hline A & Yes & No & No \\
\hline B & No & Yes & No \\
\hline C & Yes & Yes & Yes \\
\hline & Yes & Yes & Yes / No? \\
\hline
\end{tabular}

In this account, rationality is interpreted somewhat differently than in Habermas. It requires consistency between the evaluation of premises and the evaluation of outcomes. While the discursive dilemma renders doubtful the Habermasian harmony between fair procedures and rational outcomes, Pettit nevertheless insists, with Habermas, on the importance of rationality for democratic legitimacy. He argues that for legitimacy, the goal is to contain, as far as possible, the occurrence of inconsistencies between the evaluation of premises and the evaluation of the outcomes themselves. His response to the discursive dilemma is to advocate a premise-based procedure. Such procedures privileges the collective evaluation of the premises and demands that the outcome supported by the conclusion that follows from a particular stance on the premises is chosen. In the example above, the premisebased procedure would yield a positive decision - even though, if asked directly, the 
majority would decide not to build. Pettit argues that only the premise-based procedure will make a collective agency "conversable" - answerable to reason. ${ }^{8}$

I agree with Pettit - against Habermas - that we ought to be skeptical about the rationalizing potential of deliberative democracy, but his skepticism does not go far enough. To force upon a democratic collective a particular outcome merely because it can be seen as the conclusion of premises that are endorsed by some majoritarian democratic process, is to try and enforce rationality when it is absent. On this basis, I think we should reject Pettit's interpretation of the rationality requirement of legitimacy.

This leads me to introduce the second category of conceptions of democratic legitimacy, where rationality conditions are dropped entirely. Conceptions of democratic legitimacy of this category limit the requirements of legitimacy to procedural conditions. I call this category Pure Proceduralism. According to such conceptions, an outcome is legitimate if it is the outcome of an appropriately constrained decision-making process, i.e. one that satisfies conditions of political fairness. The view defended by Thomas Christiano in his book The Rule of the Many is an example. According to him,

“democratic discussion, deliberation, and decisionmaking under certain conditions are what make the outcomes legitimate for each person. ...

\footnotetext{
${ }^{8}$ According to Pettit (2001a: 111): "every purposive group is bound to try to collectivize reason, achieving and acting on collective judgments that pass reason-related tests like consistency.” This entails that " $[\mathrm{u}]$ nder the regime of deliberative democracy, it is required that with any logically connected propositions in the domain of discussion - the premises and conclusions of our examples people make up their minds about the propositions in such a way that reason is satisfied" (Pettit 2001b: 276). See also List (2004) for a discussion of the conclusions Pettit draws from the discursive dilemma for collective rationality and democratic legitimacy.
} 
[W]hatever the results of discussions, deliberation, and decisionmaking ..., they are legitimate. The results are made legitimate by being the results of the procedure" (Christiano 1996: 35).

Another example is the view defended by Gerald Gaus (1997). He argues that the deliberative process inevitably produces disagreements about what should count as the best decision that cannot be reconciled. Without agreement, there is no other justification for a particular decision to be had other than it being the result of a fair process. ${ }^{9}$

Without being able to argue the case here (see Peter 2007), I think that Pure Proceduralism offers a better conception of legitimacy than Rational Proceduralism. In the next section, I shall argue that Rawls' conception of democratic legitimacy is best interpreted as a version of Pure Proceduralism. Against this background, I shall also defend his idea of public reason - in its procedural interpretation. This implies, of course, that we should reject the substantive interpretation of Rawls' idea of public reason.

\section{Justice, Legitimacy, and Public Reason}

Rawls' developed his conception of legitimacy in Political Liberalism, and provided some elaboration in his "Reply to Habermas" (Rawls 1993, 1995). Because he treats legitimacy as related to justice, however, his earlier work and Justice as Fairness: A Restatement are relevant as well (Rawls 1971, 2001). Let me first focus on how Rawls conceives of the relationship between justice and legitimacy, and then move on to a more detailed discussion of his conception of legitimacy.

\footnotetext{
9 "In his or her deliberations, each citizen presents what he or she believes is the best public justification; the voting mechanism constitutes a fair way to adjudicate deep disagreements about what is publicly justified" (Gaus 1997: 234)
} 
Rawls states:

"In justice as fairness, and I think in many other liberal views, the guidelines of inquiry of public reason, as well as its principle of legitimacy, have the same basis as the substantive principles of justice (Rawls 1993: 225). ${ }^{10}$ The common basis between justice and legitimacy is formed, first of all, by the fundamental ideas that underlie Rawls' theory of justice as fairness and that he sees as implicit in the political culture of democratic societies. Two such ideas are of particular importance. The first is the idea of society as a fair system of cooperation; the second is the idea of citizens as free and equal persons.

To start with the latter, Rawls' political conception of the person attributes to citizens two principal moral powers. These are, on the one hand, the capacity for a conception of the good and, on the other, the capacity for a sense of justice. ${ }^{11}$ By virtue of the capacity for a conception of the good, the citizens know what is to their own advantage. It gives them the capacity to be rational. The capacity for a sense of justice, on the other hand, stresses the capacity to be reasonable. ${ }^{12}$ Citizens are reasonable insofar as they recognize that, though they have good reasons to hold their own conception of the good, there are good reasons for other citizens to hold different views. They are reasonable if they are willing to propose fair terms of cooperation and if they accept what Rawls calls the burdens of judgment - theoretical limits to the use of reason. $^{13}$

\footnotetext{
${ }^{10}$ See also Rawls (1995: 170ff.)

${ }^{11}$ On this see Rawls (1971: §77). The role of the conception of the person in justice as fairness is worked out in greater detail in his later work; see for example Rawls (1982a 164ff, 1993: I. 4, II and V).

${ }^{12}$ On the distinction between the reasonable and the rational, see Rawls (1993: II. 1-3 and VIII. 4).

${ }^{13}$ On the burdens of judgment, see Rawls (1993: II. 2).
} 
This links the first fundamental idea to the second - the idea of society as a fair system of cooperation. A conception of society based on cooperation entails that everybody is viewed as part of this cooperation and has a right to the benefits produced. ${ }^{14}$ Given their capacity for a sense of justice, the citizens are assumed to be willing to propose fair terms of cooperation which guarantee fair prospects for all citizens for the pursuit of their respective rational advantage. A conception of justice that is fair, according to Rawls, should respect and ensure equal liberties for the citizens to develop and pursue their (reasonable) conceptions of the good.

These two fundamental ideas, together with the idea that a conception of justice should be freestanding, i.e. not draw on any comprehensive doctrine of the good, and the idea that justice should apply to society's basic institutions make justice as fairness a political conception of justice (Rawls 1993: I; 2001: 26). Rawls developed his own proposal of justice as fairness starting from these ideas, and they form the common basis between justice and legitimacy.

What distinguishes the requirements of legitimacy from those of justice? Rawls defines legitimacy in the following way:

"political power is legitimate only when it is exercised in accordance with a constitution (written or unwritten) the essentials of which all citizens, as

\footnotetext{
${ }^{14}$ "Cooperation is distinct from merely socially coordinated activity, for example, from activity coordinated by orders issued by some central authority. Cooperation is guided by publicly recognized rules and procedures that those cooperating accept and regard as properly regulating their conduct" (Rawls 1993: 16). And: "Cooperation involves the idea of fair terms of cooperation [...]. Fair terms of cooperation specify an idea of reciprocity: all who are engaged in cooperation and who do their part as the rules and procedures require, are to benefit in an appropriate way as assessed by a suitable benchmark of comparisons" (ibid.).
} 
reasonable and rational, can endorse in the light of their common human reason" (Rawls 2001: 41).

"Constitutional essentials" is a Rawlsian technical term. There are two aspects to these essentials:

a. fundamental principles that specify the general structure of government and the political process: the powers of the legislature, executive and the judiciary; the scope of majority rule; and

b. equal basic rights and liberties of citizenship that legislative majorities are to respect: such as the right to vote and to participate in politics, liberty of conscience, freedom of thought and of association, as well as the protections of the rule of law. ${ }^{15}$

These constitutional essentials set the framework within which the democratic process is to take place and determine the legitimacy of democratic decisions. Only when the process of deliberative politics is appropriately embedded in such a framework, can the decisions made in the course of this process claim legitimacy.

What is the appropriate criterion for this framework? Rawls answers that it has to respect the first principle of justice, but not the second principle:

"A principle specifying the basic rights and liberties covers the second kind of constitutional essentials. But while some principle of opportunity is surely such an essential, for example, a principle requiring at least freedom of movement and free choice of occupation, fair equality of opportunity (as I have specified it) goes beyond that and is not such an essential. Similarly, though a social minimum providing for the basic needs of all citizens is also an essential, what I

\footnotetext{
${ }^{15}$ Rawls (1993: 227).
} 
have called the 'difference principle' is more demanding and is not" (Rawls 1993: 228f).

It follows that for Rawls, legitimacy is related to but weaker than justice. Just situations are also legitimate, but democratic decisions can be legitimate without being just. For legitimacy, it is sufficient if the first principle of justice as fairness is satisfied. Because this principle guarantees the fair value of the political values, it does not refer to basic rights and liberties only. A social minimum of all primary goods must be guaranteed to achieve a fair value of the political liberties. Still, the legitimacy requirement is weaker than what the two principles of justice as fairness taken together stipulate. $^{16}$

How does Rawls' idea of public reason fit in the conception of legitimacy? To answer this question, we first need a better understanding of the idea itself. It has, according to Rawls, five aspects:

"(1) the fundamental political questions to which it applies; (2) the persons to whom it applies (government officials and candidates for public office); (3) its content as given by a family of reasonable political conceptions of justice; (4) the application of these conceptions in discussions of coercive norms to be enacted in the form of legitimate law for a democratic people; and (5) citizens'

\footnotetext{
${ }^{16}$ Rawls (1995: 175) writes: "legitimacy is a weaker idea than justice and imposes weaker constraints on what can be done. ... [D]emocratic decisions and laws are legitimate, not because they are just but because they are legitimately enacted in accordance with an accepted legitimate procedure. It is of great importance that the constitution specifying the procedure be sufficiently just, even though not perfectly just ... But it may not be just and still be legitimate, provided it is just enough in view of the circumstances and social conditions."
} 
checking that the principles derived from their conceptions of justice satisfy the criterion of reciprocity" (1999: 574f). ${ }^{17}$

Rawls emphasizes that all five aspects always need to be considered together. But some of these aspects need more elucidation than others. The idea of public reason aims to tackle the problem of political legitimacy characterized above, i.e. how it is possible, given the fact of reasonable pluralism, for citizens to justify the terms of the system of cooperation to each other. He solves this problem by applying the method of "political" - as opposed to "metaphysical" - justification that he has developed in response to critics of his theory of justice as fairness (Rawls 1985). Rawls thus conceives of public reason as "freestanding" in the same way as his theory of justice is. That is, the goal is to characterize the idea of public reason with reference to fundamental political values alone and make it independent of comprehensive doctrines. This restricts the content of public reason (aspect 3) to what constitutes the family of political conceptions of justice. Because the content of public reason is thus restricted, its proper domain in the political sphere at large must be carefully specified. Rawls conceives of public reason as limited to matters of constitutional essentials and basic justice (aspect 1). ${ }^{18}$ In addition, an account of the person to whom public reason applies and how (aspects 2, 4, and 5) also needs to be given. For it is obvious that in many contexts, we will reason about political matters in terms of non-

\footnotetext{
${ }^{17}$ Rawls adds: "Moreover, such reason is public in three ways: as the reason of free and equal citizens, it is the reason of the public; its subject is the public good concerning questions of fundamental political justice, which questions are of two kinds, constitutional essentials and matters of basic justice; and its nature and content are public, being expressed in public reasoning by a family of reasonable conceptions of political justice reasonably thought to satisfy the criterion of reciprocity" (1999: 575). 18 "In matters of constitutional essentials, as well as on questions of basic justice, we try to appeal only to principles and values each citizen can endorse" (Rawls 2001: 41).
} 
public reason. ${ }^{19}$ The question is: in what context is it important that the restriction on reason is observed? Rawls answers that the proper domain of public reason is the “public political forum” (Rawls 1999: 575) and applies primarily - but not only - to judges, government officials, and candidates for public office. The public political forum is a separate domain contained within what Rawls calls the "public political culture". The latter is a normative category, encompassing all reasonable comprehensive doctrines. It is to be distinguished from "the background culture", of which civil society forms an important part. The background culture is a descriptive category. It captures actual public debates. These actual debates may be influenced by unreasonable doctrines.

With these conceptual and terminological distinctions in place, we are now in a position to address the main question that this paper aims to answer: how should we conceive of the relationship between Rawls' conception of democratic legitimacy and his idea of public reason? The answer will depend on how the relation between the public political forum - where only public reason applies - and the public political culture is specified. Does Rawls' conception of democratic legitimacy demand that deliberation is reducible to public reason, or does it allow for the deliberative process in the public political culture to invoke a broader set of considerations?

If Rawls' conception of democratic legitimacy was of the Rational Proceduralist category, we would have to go with the substantive interpretation of Rawls' idea of public reason. In this view, legitimacy demands that the substantive reasons given in the public political culture to support democratic decisions are identical - at least in principle - with the demands of public reason. This would imply

\footnotetext{
${ }^{19}$ Non-public reason is "the reason appropriate to individuals and associations within society" (2001: 92).
} 
that in the deliberative process, people ought not make reference to their comprehensive doctrines, but instead attempt to justify their views to each other purely on the basis of - freestanding - public reason.

If Rawls' conception of democratic legitimacy was of the Pure Proceduralist category, however, the demands on the deliberative process are less restrictive. This conception of democratic legitimacy fits with the procedural interpretation of Rawls' idea of public reason. In this interpretation, it is sufficient that the process in which decisions are taken and people exchange reasons for and against particular decisions is appropriately constrained. Public reason only applies to the justification of the constitution that constrains the process of democratic decision-making, but is not required to extend to the substantive (as opposed to the procedural) reasons people might hold to justify a decision. This implies that in the deliberative process, people need not argue solely on the basis of public reason. It is acceptable that they draw on their comprehensive doctrines. Because the public political culture denotes the normatively limited domain of reasonable conceptions, the deliberative process at all times respects the constraints imposed by the constitution, and public reason is available to remind people of these constraints. The procedural interpretation thus insists on the difference between being reasonable - drawing on a comprehensive doctrine that is compatible with the political conception of justice - and employing public reason - arguing only from within a political conception of justice.

Unfortunately, Rawls is not always very clear about how we should interpret his idea of public reason, and hence about how to interpret his conception of democratic legitimacy. Some parts of his writings suggest a substantive interpretation while others suggest a procedural interpretation of his idea of public reason. This, I contend, has created much confusion in the literature. Let me first give some 
examples for either interpretation. I shall then, in a final step, argue that we should adopt the procedural interpretation of his idea of public reason.

At one point, Rawls writes that public reason is the "form of reasoning appropriate to equal citizens who as a corporate body impose rules on one another backed by sanctions of state power" (Rawls 2001: 92). This reads just like a description of what a democratic society does when it decides on some laws or policies and thus suggests that public reason ought to apply to the deliberative process at large. A further piece of evidence for the substantive interpretation may be found in some of what Rawls has to say on the relationship between public and non-public reason. To a certain extent, Rawls regards it as admissible if, in the public political culture, citizens put forward non-public reasons. He demands, however, that what he calls the proviso is satisfied. Non-public reasons, i.e. reasons based on comprehensive doctrines, are admissible in the deliberative process if, "in due course proper political reasons ... are presented that are sufficient to support whatever the comprehensive doctrines introduced are said to support" (Rawls 1999: 591). This, again, seems to suggest that the content of the reasons exchanged in the public political culture must ultimately be describable in terms of the content of public reason.

What about passages that suggest the procedural interpretation? Consider, first, what Rawls says on "political goodness". He writes: "citizens want to cooperate politically with one another in ways that satisfy the liberal principle of legitimacy: that is, on terms that can be publicly justified to all in the light of shared political values" (Rawls 2001: 202). What this characterization expresses is that political goodness - the realm of shared political values - can only be invoked to justify the constraints that shape the political process. According to the view Rawls expresses here, legitimacy requires that the process satisfy constraints everyone can accept. It 
does not entail that a particular outcome of the deliberative exchange of reasons ought to be justifiable in that way.

Other passages of Justice as Fairness: A Restatement, similarly suggest that the shared political values that define the content of public reason ought to be invoked in the justification of the constitutional essentials and, in the context of justice instead of legitimacy, of the two principles of justice. ${ }^{20}$ Rawls also emphasizes that he does not want to "say that a political conception formulates political values that can settle all legislative questions" (Rawls 2001: 41). ${ }^{21}$ And he notes "if a political conception of justice covers the constitutional essentials, it is already of enormous importance even if it has little to say about many economic and social issues that legislative bodies must consider (Rawls 2001: 28). ${ }^{22}$ Since the political conception of justice

\footnotetext{
20“'In matters of constitutional essentials, as well as on questions of basic justice, we try to appeal only to principles and values each citizen can endorse. A political conception of justice hopes to formulate these values: its shared principles and values make reason public, while freedom of speech and thought in a constitutional regime make it free" (Rawls 2001: 41). Or when he argues that public reason is one part of the original agreement, the first part being the two prinicples of justice. The second part is on "principles of reasoning and the rules of evidence in the light of which citizens are to decide whether the principles of justice apply, when and how far they are satisfied and which laws and policies best fulfill them in existing social conditions" (Rawls 2001: 89).

${ }^{21} \mathrm{He}$ also notes the following, however: "It is a further desideratum that all legislative questions that concern or border on these [constitutional] essentials or are highly divisive, should also be settled, as far as possible, by guidelines and values that can be similarly understood" (Rawls 2001: 41).

${ }^{22}$ The paragraph continues (Rawls 2001: 28): “To resolve these issues it is often necessary to go outside that conception and the political values its principles express, and to invoke values and considerations that it does not include. But as long as there is firm agreement on the constitutional essentials, the hope is that political and social cooperation between free and equal citizens can be maintained."
} 
defines the content of public reason, this constitutes more evidence for the procedural interpretation.

A final piece of evidence is the way in which Rawls draws the distinction between justice and legitimacy in the "Reply to Habermas". There, Rawls argues that because "it is unreasonable to expect in general that human statutes and laws should strictly be just by our lights" (1995: 148, fn 30), a person may accept that a particular policy or law is legitimate, even if she does not regard it as justified. Rawls thus insists that "citizens recognize the familiar distinction between accepting as (sufficiently) just and legitimate a constitution with its procedures for fair elections and legislative majorities, and accepting as legitimate (even when not just) a particular statute or a decision in a particular matter of policy" (1995: 148).

Which interpretation of Rawls' idea of public reason should we adopt? The substantive interpretation, which fits Rational Proceduralism, or the procedural interpretation, which fits Pure Proceduralism? In my view, the confusion about Rawls' idea of public reason is a consequence of his failure to distinguish clearly between these two conceptions of legitimacy and their implications for the role of public reason.

It seems clear to me that even though the textual evidence I have cited supports both, Rawls' conception of legitimacy has to be Pure Proceduralist and cannot be a version of Rational Proceduralism. First, if he did indeed advocate Rational Proceduralism, his "Reply to Habermas" would not make sense. When Rawls insists on how the limited domain of his project distinguishes it from Habermas' project, he is not just insisting on a difference in degree, but on a difference in kind. For Habermas, the question is whether we can rationally justify a course of action to each other (under ideal circumstances). For Rawls, the question is 
what we can rationally justify to each other, and his answer is: not much. This is why he insists on the priority of the basic structure, and focuses, in his conception of legitimacy, on the justification of constitutional essentials.

Public reason is invoked not just in the original justification of the constitution, but also plays a role in cases where the legitimacy of particular decisions is in question. In the Rational Proceduralist view, this issue has to be settled with regard to the content of public reason. In the Pure Proceduralist view and its procedural interpretation of public reason, public reason is invoked to appeal to the shared basis offered by the political values that constrain the democratic process. The question to be answered is not whether a particular decision can be supported by substantive reasons everyone can accept, but whether the decision came about through a process that is in line with the shared values.

The procedural interpretation of public reason is in line with Rawls' view on public justification. The idea is introduced precisely for when questions of legitimacy (or justice) are contested. ${ }^{23}$ Rawls conceives of public justification as having a limited domain, and as aiming at consensus: "Public justification is not ... simply valid argument from given premises (though of course it is that)... [W] hen the premises and conclusions are not acceptable on due reflection to all parties in disagreement,

\footnotetext{
${ }^{23}$ "So understood, justification is addressed to others who disagree with us. If there is a conflict in judgment about questions of political justice - judgements about the justice of certain principles and standards, particular institutions and policies, and the like - there is nothing so far to justify. To justify our political judgments to others is to convince them by public reason, that is, by ways of reasoning apporpriate to fundamental political questions, and by appealing to beliefs, grounds, and political values it is reasonable for others also to acknowledge. Public justification proceeds from some consensus: from premises all parties in disagreement, assumed to be free and equal and fully capable of reason, may reasonably be expected to share and freely endorse" (Rawls 2001: 27).
} 
valid argument falls short of public justification" 2001: 27). The idea is that if there is disagreement, appeal to the consensus on which the political conception of justice rests helps to resolve conflicting questions. The substantive interpretation of Rawls' idea of public reason would amount to the unrealistic hope that this consensus can all of a sudden be enlarged to cover more substantive ground. The procedural interpretation, meanwhile, is consistent with a more modest reading of Rawls' idea of public justification. In this view, public justification amounts to referring the debate to the existing common ground on procedural considerations. Because Rawls defines the public political culture as the realm of reasonable conceptions of the good, there is, in this realm, always a possibility to appeal to a shared basis. While all sorts of reasons might be exchanged in the course of the deliberative process, when there is a conflict about whether or not a particular decision is legitimate, then public reason can be invoked and settle the question. This, I contend, is a sound interpretation of Rawls' conception of democratic legitimacy and its associated idea of public reason.

\section{References}

Christiano, Thomas. 1996. The Rule of the Many. Boulder, Co.: Westview Press.

Cohen, Joshua. 1989. “Deliberation and Democratic Legitimacy.” In Hamlin, Alan and Philip Pettit (eds.) The Good Polity. Oxford: Blackwell, pp. 17 - 34.

Freeman Samuel. 2000. "Deliberative Democracy: A Sympathetic Comment." Philosophy and Public Affairs 29(4): 371 - 418.

Gaus, Gerald. 1997. “Reason, Justification, and Consensus: Why Democracy Can’t Have It All.” In Bohman, James and William Rehg (eds.) Deliberative Democracy. Cambridge: MIT Press, pp. $205-242$. 
Habermas, Juergen. 1990. Moral Consciousness and Communicative Action. Transl. by Christian Lenhardt and Shierry Weber Nicholsen. Cambridge: MIT Press.

Habermas, Juergen. 1996. Between Facts and Norms. Transl. by William Rehg. Cambridge: MIT Press.

List, Christian. 2006. "The Discursive Dilemma and Public Reason.” Ethics 116(2): $362-402$

List, Christian and Philip Pettit. 2002. “Aggregating Sets of Judgments: An Impossibility Result.” Economics and Philosophy 18: 89 - 110.

List, Christian and Philip Pettit. 2004. "Aggregating Sets of Judgments: Two Impossibility Theorems Compared." Synthese 140(1-2): 207 - 235.

Manin, Bernard 1987. “On Legitimacy and Political Deliberation.” Political Theory $15: 338-368$.

Peter, Fabienne. 2007. "Democratic Legitimacy and Proceduralist Social Epistemology." Politics, Philosophy, and Economics, forthcoming.

Pettit, Philip. 2001a. A Theory of Freedom. Oxford: Oxford University Press.

Pettit, Philip. 2001b. "Deliberative Democracy and the Discursive Dilemma." Philosophical Issues 11: 268 - 299.

Rawls. John. 1971. A Theory of Justice. Cambridge: Harvard University Press.

Rawls, John. 1985. “Justice: Political not Metaphysical.” Philosophy and Public Affairs 14: 223 - 252.

Rawls, John. 1993. Political Liberalism. New York: Columbia University Press. Rawls, John. 1995. "Reply to Habermas.” The Journal of Philosophy 92(3): 132 180.

Rawls, John. 1999. Collected Papers. Edited by Samuel Freeman. Cambridge: Harvard University Press. 
Rawls. John. 2001. Justice as Fairness: A Restatement. Cambridge: Harvard University Press. 